\title{
COMPARISON OF LOCAL METHYLCOBALAMINE INJECTION VERSUS LOCAL BUPIVACAINE INJECTION FOR THE TREATMENT OF ACUTE HERPETIC NEURALGIA
}

\author{
Ghazala Yasmin, Naeem Raza, Arfan-Ul-Bari*, Farah Yousaf, Summaya Saleem**, Najia Ahmed* \\ Pak Emirates Military Hospital/National University of Medical Sciences (NUMS) Rawalpindi Pakistan, *Pakistan Naval Ship Shifa Hospital, Karachi Pakistan, \\ ${ }^{* *}$ Combined Military Hospital Attock/National University of Medical Sciences (NUMS) Pakistan
}

\begin{abstract}
Objective: To compare the reduction in mean pain score with local Methylcobalamin injection versus local Bupivacaine injection in patients with acute herpetic neuralgia.

Study Design: Quasi experimental study.

Place and Duration of Study: Dermatology Outpatient Department, Pak Emirates Military Hospital, Rawalpindi, from Jun to Dec 2019.

Methodology: Total 100 patients, having pain score more than 3, fulfilling the selection criteria were divided into two groups. Group A was treated with daily subcutaneous injection Bupivacaine, whereas Group B was treated with daily subcutaneous injection Methycobalamin at the site of neuralgia. Patients were followed up for 4 weeks. The pain score was noted. All the data was entered and analyzed on SPSS version 21.

Results: In this study mean age of patients in group A was $43.82 \pm 15.76$ years and in group B was $44.76 \pm 16.92$ years. The mean visual analogue pain score at 4th week in the group A patients was $1.14 \pm 0.32$ and in group B was $1.90 \pm 0.97$. Statistically significant difference was found in group A (local Bupivacaine) with visual analogue score (VAS) at 4 th week ( $p$ value=0.002).

Conclusion: The local Bupivacaine injection showed significant reduction in mean pain score than local Methylcobalamin injection in patients with acute herpetic neuralgia.
\end{abstract}

Keywords: Acute herpetic neuralgia, Bupivacaine, Methylcobalamin, Pain score.

How to Cite This Article: Yasmin G, Raza N, Bari AU, Yousaf F, Saleem S, Ahmed N. Comparison of Local Methylcobalamine Injection Versus Local Bupivacaine Injection for The Treatment of Acute Herpetic Neuralgia. Pak Armed Forces Med J 2021; 71(6): 2228-2231.

DOI: https://doi.org/10.51253/pafmj.v71i6.6464

\footnotetext{
This is an Open Access article distributed under the terms of the Creative Commons Attribution License (https://creativecommons.org/licenses/by-nc/4.0/), which permits unrestricted use, distribution, and reproduction in any medium, provided the original work is properly cited.
}

\section{INTRODUCTION}

Herpetic neuralgia is a type of neuropathic pain syndrome which occurs in dermatome of herpes zoster skin lesions and may persist for 3 months or more. Among the patients of herpes zoster, around $20 \%$ of patient experience neuralgia. Major risk factors are prodromal pain, severe rash, and zoster in ophthalmic branch of trigeminal nerve. Depending upon the duration of neuralgia from onset of rash, herpetic neuralgia is divided into three types, acute (within a month), subacute (1-3 months) and post herpetic neuralgia (beyond three months)..$^{1-3}$

Treatment modalities used for herpetic neuralgia includes medical (systemic tricyclic antidepressants, anticonvulsants and opioids), topical (Lidocaine, Tramadol and Capsaicin), interventional (local injections, nerve blocks and nerve stimulation) therapies and conventional (Acupoint injection). ${ }^{4,5}$

Methycobalamin has an important role in myelin

Correspondence: Dr Ghazala Yasmin, Graded Dermatologist, Pak Emirates Military Hospital, Rawalpindi Pakistan

Received: 17 Mar 2021; revision received: 13 Jul 2021; accepted: 26 Jul 2021 sheath synthesis and integrity. It regenerates myelin sheath of damaged nerves and restores their functions. Reduced level of vitamin B12 is associated with high risk of neuralgia. Bupivacaine is a long acting local anesthetics which inhibit voltage-gated sodium channels and decreases pain by blocking impulses in peripheral nerves. $2,6,7,8$

Objective of this study was to compare the mean pain score after treatment with local subcutaneous Bupivacaine injection versus local subcutaneous Methylcobalamin injection in patients with acute herpetic neuralgia. We conducted this study to get the evidence in local setting and role of these drugs in acute herpetic neuralgia.

\section{METHODOLOGY}

This quasi experimental study was conducted at the Dermatology Outpatient Department, Pak Emirates Military Hospital, Rawalpindi, from January to June 2018, after taking permission from Institutional Ethical Committee (ltr no. A/8/EC/270/2021). Sample size of 100 cases; 50 cases in each group is calculated with $5 \%$ level of significance, $80 \%$ power of test and 
taking mean pain score after treatment i.e. $5.75 \pm 0.79$ with Bupivacaine injection and $3.2 \pm 1.61$ with Methylcobalamin injection for acute herpetic neuralgia. Sampling technique was non probability, consecutive sampling.

Inclusion Criteria: Patients of either gender with age ranging from 19-70 years, presenting in Outpatient department with acute herpetic neuralgia were included in the study.

Exclusion Criteria: Pregnant females, patient with known allergy to Bupivacaine or Methylcobalamin, patient with localized abscess at site of injection, patient with known diabetes mellitus (BSR $>186 \mathrm{mg} / \mathrm{dl}$ ) or ischemic heart disease or any previous history of arrhythmia, were excluded from study.

One hundred patients, having pain score more than 3 at dermatome of herpes zoster skin lesions that occurs within a month after the onset of rash, fulfilling the inclusion criteria was selected from Outpatient Department of Dermatology, Pak Emirates Military Hospital, Rawalpindi. Informed consent was obtained from patients. Demographic details including age and sex was also noted. Patients were divided in two equal groups by using lottery method. Group A patients received subcutaneous Bupivacaine $0.5 \%$ in affected dermatome once daily for 4 weeks. Group B, patients received subcutaneous Methylcobalamin in affected dermatome once daily for 4 weeks. Dose of drug varies from 1-2 injections depending on involved surface area. Then patients were followed-up in OPD for 4 weeks. Pain score was measured by using visual analogue pain scale which is a subjective measure for pain. Scores were recorded by making a handwritten mark on a $10 \mathrm{~cm}$ line that represents a continuum between "no pain" and "worst pain." 1-3 indicates mild pain, 47 indicates moderate pain while 8-10 indicates worst pain. All data was recorded on a proforma.

All collected data was entered into Statistical Package for the social sciences (SPSS) version 21 and analyzed. Quantitative data like age and baseline and after treatment pain score was presented as mean and standard deviation. Qualitative data like gender and site of neuralgia was presented as frequency and percentage. Independent sample t-test was applied to compare mean pain score between both groups. The $p$ value of $\leq 0.05$ was taken as significant.

\section{RESULTS}

In this present study, total 100 patients were enrolled. The mean age of the group A patients was
$43.82 \pm 15.76$ years and in group B patients, it was 44.76 \pm 16.92 years.

Forty patients were male and sixty were females. Out of male patients, 21 (52.5\%) were in group A and $19(47.5 \%)$ in group B, similarly the female patients were $29(48.3 \%)$ and $31(51.7 \%)$ in group A and B respectively.

Trigeminal dermatome was the most commonly involved area, whereas sacral dermatome was the least involved. The mean value of visual analogue score at baseline of the group A patients was $6 \pm 1.46$ and its mean value in group B was $6.24 \pm 1.46$. Mean visual analogue score at 4 th week were $1.14 \pm 1.32$ and $1.90 \pm$ 0.97 in group A and B respectively. Statistically significant difference was found between the study groups i.e. $p$-value $=0.002$ (Table-I) .

Table-I: Comparison of visual analogue score before treatment and at 4th week of treatment with study groups.

\begin{tabular}{l|c|c|c}
\hline \multirow{2}{*}{$\begin{array}{l}\text { Visual Analogue } \\
\text { Pain Score }\end{array}$} & $\begin{array}{c}|c| \\
\text { Group A } \\
\text { (Bupivacaine) } \\
\text { (n=50) }\end{array}$ & $\begin{array}{c}\text { Group B } \\
\text { (Methylcobal- } \\
\text { amin) (n=50) }\end{array}$ & $\begin{array}{c}p \text { - } \\
\text { value }\end{array}$ \\
\hline $\begin{array}{l}\text { Visual Analogue } \\
\text { Pain Score before } \\
\text { treatment }\end{array}$ & $6.00 \pm 1.46$ & $6.24 \pm 1.46$ & - \\
\hline $\begin{array}{l}\text { Visual Analogue } \\
\text { Pain Score at 4 wk }\end{array}$ & $1.14 \pm 0.32$ & $1.90 \pm 0.97$ & 0.002 \\
\hline
\end{tabular}

The study results showed that in patients with age $\leq 50$ years the mean value of VAS at 4 th week in group A and B were $1.13 \pm 0.34$ and $1.87 \pm 0.97$ respectively. Similarly, in $>50$ years patients the mean value of visual analogue score at 4 th week were $1.17 \pm 1.34$ and $1.96 \pm 0.99$ respectively. Statistically significant difference was found between the study groups with Visual Analogue Score at 4th week in patients with age $\leq 50$ years i.e. $p$-value $=0.015$.

The male patients had the mean value of visual analogue score at 4th week in group A was $1 \pm 1.37$ and group B was $1.95 \pm 0.97$. Similarly, in female patients the mean value of visual analogue score at 4th week were $1.24 \pm 1.30$ and $1.87 \pm 0.99$ respectively. Statistically significant difference was found between the study groups with visual analogue score at 4 th week stratified by gender i.e., $p$-value $<0.05$.

On comparison of different sites of neuralgia, there was statistically significant difference between visual analogue score at 4 th week in patients having neuralgia at chest, abdomen and arms (Table-II). 
Table-II: Comparison of visual analogue score at 4 th week with study groups stratified by site of neuralgia.

\begin{tabular}{|c|c|c|c|c|}
\hline & \multirow[b]{2}{*}{ Site of Neuralgia } & \multicolumn{2}{|c|}{ Study Groups } & \multirow[b]{2}{*}{$\begin{array}{c}p \text { - } \\
\text { value }\end{array}$} \\
\hline & & $\begin{array}{c}\text { Group A } \\
\text { (Bupivacaine) } \\
(\mathrm{n}=50)\end{array}$ & $\begin{array}{c}\text { Group B } \\
\text { (Methycobal- } \\
\text { amin) }(n=50)\end{array}$ & \\
\hline \multirow{8}{*}{ 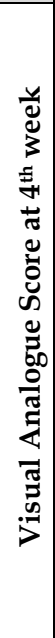 } & $\begin{array}{l}\text { Trigeminal derma- } \\
\text { tomes on face }\end{array}$ & $1.11 \pm 1.36$ & $1.43 \pm 0.97$ & 0.612 \\
\hline & $\begin{array}{l}\text { Cervical derma- } \\
\text { tomes on neck }\end{array}$ & $1.00 \pm 1.73$ & $1.5 \pm 0.76$ & 0.671 \\
\hline & $\begin{array}{l}\text { Cervical derma- } \\
\text { tomes on arms }\end{array}$ & $1.5 \pm 1.22$ & $2.86 \pm 0.69$ & 0.029 \\
\hline & $\begin{array}{l}\text { Thoracic derma- } \\
\text { tomes on chest }\end{array}$ & $0.86 \pm 1.21$ & $2.75 \pm 0.95$ & 0.026 \\
\hline & $\begin{array}{l}\text { Thoracic derma- } \\
\text { tomes on abdomen }\end{array}$ & $0.50 \pm 0.93$ & $1.71 \pm 0.76$ & 0.016 \\
\hline & $\begin{array}{l}\text { Lumber derma- } \\
\text { tomes on legs }\end{array}$ & $1.25 \pm 1.49$ & $1.40 \pm 0.89$ & 0.844 \\
\hline & $\begin{array}{l}\text { Sacral derma- } \\
\text { tomes on legs }\end{array}$ & $2.00 \pm 1.55$ & $1.80 \pm 1.30$ & 0.824 \\
\hline & $\begin{array}{l}\text { Sacral derma- } \\
\text { tomes on } \\
\text { genitalia }\end{array}$ & $1.00 \pm 1.73$ & $1.43 \pm 0.97$ & 0.231 \\
\hline
\end{tabular}

\section{DISCUSSION}

Herpetic neuralgia is a chronic neuropathic pain in the region of the herpes zoster rash and may persist even after healing of the cutaneous lesions. Acute herpetic neuralgia is thought to be due to nerve damage caused by herpes zoster, leading to ganglionitis and neuritis. This cause excessive sympathetic stimulation and vasoconstriction of the endoneural arterioles present in the nerves. This leads to decrease blood flow in the intraneural capillary bed resulting in nerve ischemia. Endoneural edema can develop if ischemia is persistent, which increasess the endoneural pressure and compromises the endoneural blood flow. As a final result, nerve damage becomes severe and irreversible. ${ }^{11}$

Paravertebral nerve block was used by Naja to relieve pain in post-herpetic neuralgia using repetitive injections of local anesthetic mixture (Bupivacaine 0.5\% $19 \mathrm{ml}$ and Clonidine $150 \mu \mathrm{g} / \mathrm{ml}-1$ ) every 48 hours for three weeks, using a catheter inserted at the T 2 -T 3 level. There were no complications, the patient remained pain-free for over an 8-month follow-up period, but evidence to support this treatment is weak. ${ }^{12}$

A study was carried out in patients with acute herpetic neuralgia in thoracic herpes zoster by Makharita et al. A single thoracic paravertebral injection of $25 \mathrm{mg}$ Bupivacaine, plus 8mg Dexamethasone in a total volume of $10 \mathrm{~mL}$ was given in active group as compared to placebo. Significantly shorter duration of pain and herpetic eruption was noticed in the active group vs. placebo group ( $p=0.013$ and $<0.001$, respectively). However, incidence of PHN was lower in active treatment group at 6 months. ${ }^{13}$

In majority of studies done with Bupivacaine, the drug was given as nerve block. None of them compared Bupivacaine with Methylcobalamin. For example, one study conducted by Akhtar et al. ${ }^{9}$ showed that the mean pain score was $5.75 \pm 0.7$ with Bupivacaine injection in acute herpetic neuralgia patients. The Bupivacaine was given as nerve block which requires trained hands. Local subcutaneous injection, as done in present study, does not require such expertise.

Studies have shown that Bupivacaine combined with Methylprednisolone reduced the postoperative pain and swelling compared with the use of Lidocaine and placebo, lidocaine and methylprednisolone, or Bupivacaine and placebo. ${ }^{14}$

Study done by $\mathrm{Xu}$ et al. showed that the mean pain score was $3.2 \pm 1.6$ with Methyl-cobalamin injection given in patients having subacute herpetic neuralgia. ${ }^{10} \mathrm{Xu}$ et al, in his another study, described that the local Methylcobalamin injection in combination with lidocaine may be an effective and safe drug in relieving pain of acute herpetic neuralgia as compared to intra muscular Methyl-cobalamine along with local lidocaine injection (short acting local anaesthetic as compared to Bupivacaine). ${ }^{15}$

Another study by Xu et al. demonstrated that local administration of Methylcobalamin can be an effective therapeutic option for subacute ophthalmic herpetic neuralgia as compared to oral and intramuscular Methylcobalamin the study describes Methylcobalamin effects on subacute neuralgia wherein our study effects of same drug is measured in acute neuralgia.16

Chen et al. noticed no significant difference between intramuscular Methylcobalamin given for 3 days in acute herpetic neuralgia as compared to placebo. ${ }^{17}$

One more study concluded that the Methylcobalamin combined with Lidocaine as subcutaneous injection improves cutaneous healing of the affected area, along with a significant and sustained analgesic effect on acute ophthalmic herpetic neuralgia. Incidence of post-herpetic neuralgia was also significantly decreased in these patients. ${ }^{18}$ However in this study, Methylcobalamin is used in combination with Lidocaine and not as a single therapeutic agent.

Above mentioned studies show Methylcobalamin as a good analgesic in herpetic neuralgia but there is limited data in literature comparing Methylcobalamin 
with Bupivacaine. Keeping this in view, further studies are recommended to be conducted to evaluate the results of our study.

\section{LIMITATION OF STUDY}

Side effects and safety profile of drugs has not been addressed. Daily local painful injections for 28 days are agonizing for the patients. It is also difficult for them to daily visit the hospital. Hospital admission can facilitate the patient but it causes more financial burden on the hospital. Moreover, visual analogue scale is a subjective measurement of pain and more susceptible to misinterpretations.

\section{CONCLUSION}

Local Bupivacaine injection showed significant reduction in mean pain score than to local Methylcobalamin injection in patients with acute herpetic neuralgia.

\section{Conflict of Interest: None.}

\section{Authors' Contribution}

GY \& NR: Direct contribution, AUB, FY, SS: Intellectual contribution, NA: Proof reading.

\section{REFERENCES}

1. Jha A, Siddalingappa K, Herakal K, Malhotra K. Randomized study to compare the effect of pregabalin with fixed-drug combination of pregabalin and Methylcobalamin in the patients of postherpetic neuralgia. Ind J Pain 2018; 32(2): 63-67.

2. Anh L, Ivan U, Melis Y, Luc F, Anthony A, Jae H et al. Postherpetic neuralgia: current evidence on the topical film-forming spray with bupivacaine hydrochloride and a review of available treatment strategies. Adv Ther 2020; 37(5): 2003-2016.

3. Weissmann JS, Smith PF. Post-herpetic neuralgia - a review of current management and future directions. Expert Opin Pharmacother 2017; 18(16): 1739-1750.

4. Chia S, Ying C, Hsuan C, Chien C. Interventional treatments for postherpetic neuralgia: a systematic review. Pain Physician 2019; 22(3): 209-228.

5. Xu G, Zhou CS, Tang WZ, Xu J, Xu G, et al. Neuroprotective effect of surround needling combined with acupoint injection on acute herpetic neuralgia. Zhongguo Zhen Jiu 2019; 39(4): 371-376.

6. Wanga J, Wu Y, Liuc S, SLin Y, Lu P. Vitamin B12 for herpetic neuralgia: a meta-analysis of randomised controlled trials. Complement Ther Med 2018; 41(12): 277-282.
7. Deepika D, Shilpa M, Doshi M, Tripathi D. A Clinical comparison of safety and efficacy of levobupivacaine and bupivacaine in supraclavicular brachial plexus block: a prospective, randomized, double blind, clinical trial. Int J Res Med 2016; 5(2); 88-94.

8. Nootriment. Methylcobalamin Injection Uses, Doses \& Negative Side Effects. [Internent] Available at: https://nootriment.com/ Methylcobalamin-injection/. [Accessed on Jan 20, 2018].

9. Akhtar FM, Rehman MM, Ahmed M, Akmal M, Mushtaq S. Pain relief in neuropathic pain-a comparison between $0.5 \%$ Bupivacaine and $0.5 \%$ Bupivacaine streptomycin combination. Pak Armed Forces Med J 2016; 66(2): 244-249.

10. Xu G, Lv ZW, Feng Y, Tang WZ, Xu GX. A single center randomized controlled trial of local methylcobalamin injection for subacute herpetic neuralgia. Pain Med 2013; 14(6): 884-894.

11. Makharita MY. Prevention of post-herpetic neuralgia from dream to reality: a ten-step model. Pain Physician 2017; 20(1): E209-E220.

12. Naja ZM, Maaliki H, Tannir MA, Rajab M, Zaida F, Zeidan A. repetitive paravertebral nerve block using a catheter technique for pain relief in post-herpetic neuralgia. Br J Anaesth 2006; 96(3): 381-383.

13. Makharita MY, Amr YM, Bayoumy Y. Single Paravertebral injection for acute thoracic herpes zoster: a randomized controlled trial. Pain Pract 2015; 15(3): 229-235.

14. Christensen J, Matzen LH, Vaeth M, Wenzel A, Schou S. Efficiency of Bupivacaine versus lidocaine and methylprednisolone versus placebo to reduce postoperative pain and swelling after surgical removal of mandibular third molars: A randomized, double-blinded, crossover clinical trial. J Oral Maxillofac Surg 2013; 71(9): 1490-1499.

15. Xu G, Xu S, Tang WZ, Chao C, Xu J. Local injection of Methylcobalamin combined with lidocaine for acute herpetic neuralgia. Pain Med 2016; 17(3): 572-581.

16. Gang X, Zhou CS, Tang WZ, Xu J, Chao C, Wang LD, et al. Local administration of methylcobalamin for subacute ophthalmic herpetic neuralgia: a randomized, phase III clinical trial. Pain Pract 2020; 20(8): 838-849.

17. Chen YC, Lu PH, Po-HL. Letter to Editor: The efficacy of intramuscular injection of vitamin B12 in the treatment of acute herpetic neuralgia-a prospective pilot study. Med J Altern Complement Med 2021; 27(6): 525-526.

18. Xa G, Xu S, Cheng C, Xú G, Tang WZ, Xu J. Local administration of methylcobalamin and lidocaine for acute ophthalmic herpetic neuralgia: a single-center randomized controlled trial. Pain Pract 2016; 16(7): 869-881. 